\title{
Other and Unspecified Parts of Biliary Tract ICD-O-3
}

National Cancer Institute

\section{Source}

National Cancer Institute. Other and Unspecified Parts of Biliary Tract ICD-O-3. NCI

Thesaurus. Code C148342.

Components of the biliary tract that are referenced in topog raphic categ ory C24 of ICD-

O-3. 